\title{
Artigos
}

\section{Prevenção do HIV/Aids em municípios da Baixada Fluminense, Rio de Janeiro, Brasil: hiatos entre a política global atual e as respostas locais}

HIV/AIDS prevention in municipalities in Baixada Fluminense, Rio de Janeiro, Brazil: gaps between global policy and local responses (abstract: p. 15)

Prevención del VIH/Sida en municipios de la Baixada Fluminense, Rio de Janeiro, Brasil: hiatos entre la política global y las respuestas locales (resumen: p. 15)

\section{Simone Monteiro ${ }^{(a)}$}

<monteiro.simone.fiocruz@gmail.com>

\section{Mauro Brigeiro(b)}

<maurobrigeiro@hotmail.com> (a,b) Laboratório de Educação em Ambiente e Saúde, Instituto Oswaldo Cruz, Fundação Oswaldo Cruz. Avenida Brasil, 4365, Pavilhão Lauro Travassos, sala 49. Rio de Janeiro, RJ, Brasil. 21045-900.

As políticas globais e nacional de resposta à Aids têm enfatizado atualmente o tratamento como prevenção, as profilaxias pós e pré-exposição ao HIV e a prevenção combinada. 0 artigo analisa a tradução dessas políticas no âmbito local, com base em uma pesquisa social em municípios da região metropolitana do Rio de Janeiro centrada no contexto programático de prevenção e cuidado do HIV/Aids e na vulnerabilidade ao HIV de gays, travestis e prostitutas. Os hiatos entre as diretrizes e os contextos locais são abordados a partir de quatro temas: ampliação da oferta de testagem; desafios das ações focalizadas; distância entre testar e tratar; e o alcance das combinações na prevenção combinada. Buscamos demonstrar a importância da compreensão dos processos sociais que perpassam a implementação das estratégias preconizadas globalmente, que precisam ainda ser consideradas no enfrentamento da epidemia.

Palavras-chave: HIV/Aids. Tratamento como prevenção. Prevenção combinada. Pesquisa social. Rio de Janeiro. 


\section{Introdução}

Em 2014 foi divulgada a proposta de eliminar mundialmente a Aids até 2030 pelo cumprimento da meta 90-90-90, o que significa testar 90\% da população com HIV, tratar $90 \%$ dos casos positivos e manter $90 \%$ das pessoas em tratamento com carga viral indetectável ${ }^{1}$. Para tanto, preconiza-se a ampliação do acesso à testagem, seguida do encaminhamento imediato dos casos identificados para tratamento, visando à redução da carga viral, principalmente entre populações com maior vulnerabilidade ao HIV, como os homens que fazem sexo com homens (HSH), pessoas trans e prostitutas, definidas como populações-chave. Essa estratégia é denominada tratamento como prevenção (TcP) ou tratamento para todas as pessoas. Almeja-se assim reduzir a circulação do HIV nos segmentos populacionais e interromper a cadeia de transmissão. Soma-se a essa estratégia a oferta das denominadas profilaxias pós (PEP) e préexposição (PrEP).

Nos documentos oficiais, essas estratégias são apresentadas como as principais promessas para erradicar a epidemia até $2030^{1}$. Ao privilegiar o controle epidemiológico, a partir do binômio "testar e tratar", as novas políticas se diferenciam das abordagens até então dominantes, centradas no uso do preservativo, na testagem atrelada ao aconselhamento e na redução das condições de vulnerabilidade ao HIV.

Um aspecto distintivo deste momento da história da epidemia é a conjugação da prevenção do HIV com o tratamento. Essa mudança de entendimento advém do fato de que os antirretrovirais, antes usados somente para o cuidado das pessoas diagnosticadas, passam a integrar os esforços para conter a propagação do vírus. Nesse sentido, tais estratégias confirmam esse novo modo de entender a prevenção e o tratamento, até então tidas como dimensões separadas. Outro traço característico desse momento é o esforço, notável nos documentos internacionais e nacionais, para que a prevenção se efetive a partir da combinação das diferentes abordagens disponíveis e segundo as especificidades e necessidades dos sujeitos. Essa proposta define o modelo da Prevenção Combinada ${ }^{2,3}$. Fundamentadas nas evidências acerca do uso dos antirretrovirais para fins de prevenção ${ }^{4,5}$, a introdução dessas novas estratégias de controle da epidemia tem mobilizado novos conceitos e reconfigurado o significado das intervençốes sanitárias ${ }^{6}$.

Conforme análises de cunho social, o incremento de novas tecnologias biomédicas para o tratamento e a prevenção vem implicando uma reordenação desse campo. Segundo uma perspectiva diacrônica, estaria em curso uma reconfiguração de investimentos, práticas e posição social dos atores envolvidos na problematização da doença e sua prevenção, assim como da relação entre respostas biomédicas e sociais ${ }^{7}$. Nessa direção, estudos apontam na última década para uma tendência à biomedicalização das respostas à epidemia, frente à ênfase nas tecnologias biomédicas, em detrimento de açóes de caráter estrutural no enfrentamento das condiçóes de vulnerabilidade ao $\mathrm{HIV}^{8}$.

Tendo em vista que o governo brasileiro tem se alinhado às atuais políticas globais de controle da Aids, este artigo visa demonstrar alguns dos desafios da sua implementação no âmbito local, a partir de uma pesquisa socioantropológica em três municípios da Baixada Fluminense, na região metropolitana do Rio de Janeiro. Abarcando diferentes dimensões empíricas e técnicas de pesquisa, o estudo buscou conhecer o contexto programático de prevenção e cuidado do HIV/Aids, que inclui a 
oferta de ações e serviços de saúde, assistência social e de tipo comunitário, bem como as condiçôes de vida e vulnerabilidade ao HIV de gays, trans/travestis e prostitutas. Os resultados foram organizados em quatro categorias de análise, quais sejam: a ampliação da oferta de testagem de HIV; os desafios das açóes focalizadas e as demandas das populações investigadas; a distância entre o testar e o tratar; e, por fim, o alcance das combinações na prevenção combinada. Tais categorias foram definidas a partir do material analisado, tendo em vista a implementação das recentes políticas de prevenção no contexto local.

\section{O estudo: origem, desenho e métodos}

A pesquisa foi formulada a partir de uma demanda do programa "Teste perto de você"(c) coordenado pela Gerência de DST/Aids da Secretaria de Estado de Saúde do Rio de Janeiro (SES). Tal programa foi desenhado para incrementar e diversificar a oferta de teste de HIV para a população geral e para as denominadas populações-chave (gays/HSH, trans/travestis e prostitutas) por meio da oferta de Unidades Móveis de Testagem (UMT) em cinco municípios da região metropolitana do Rio de Janeiro, um a cada ano. Tais municípios foram selecionados em função do perfil epidemiológico de HIV/Aids e interesse em integrar o programa. Para subsidiar sua implementação, a coordenação encomendou aos autores deste artigo uma pesquisa sobre as respostas à Aids em três municípios da Baixada Fluminense e sobre as experiências de gays, trans/travestis e prostitutas dessas localidades com os serviços de saúde. Estes seriam os últimos municípios a serem contemplados pelo programa (a partir de 2019) e privilegiariam as populaçóes-chave. Os autores aceitaram o convite e buscaram ir além das demandas advindas do programa. Imbuídos da atitude tipicamente questionadora da abordagem socioantropológica ${ }^{9,10}$, acordaram o compromisso de entender e problematizar a condução das políticas de Aids atuais, os usos e implicaçóes das tecnologias preventivas, seus atravessamentos e expressóes na vida dos grupos selecionados.

No plano metodológico, a tarefa de conduzir uma pesquisa social definida por uma abordagem multidimensional e por técnicas metodológicas diversificadas exigiu decisões estratégicas, como a conformação de uma equipe incluindo cientistas sociais e pesquisadores da área de saúde; e uma subdivisão do trabalho de campo ${ }^{(\mathrm{d})}$. $\mathrm{O}$ estudo foi realizado em 2016. A entrada no campo foi precedida por uma pesquisa sobre dados históricos, sociodemográficos e políticos da região e dos municípios estudados e pela revisão da produção acadêmica e documental sobre as estratégias de testagem e aconselhamento para gays, trans/travestis e prostitutas, dentro e fora do Brasil.

Para identificar a resposta programática ao HIV nos três municípios selecionados para o estudo, o trabalho de campo combinou diferentes métodos, todos típicos da pesquisa socioantropológica: entrevistas semiestruturadas, observação participante e grupos focais. O universo da pesquisa envolveu 74 gestores e profissionais dos Programas Municipais de DST/Aids dos três municípios, do Consultório na Rua, de outros órgãos governamentais (segurança pública e assistência social) e de ONGs. Por meio de visitas regulares aos municípios, as observaçôes participantes se deram em espaços institucionais (postos e centros de saúde) e atividades na rua (campanhas extramuros e as ações do Consultório na Rua). Foram conduzidos ainda três grupos (c) A coordenação geral do "Programa estadual de testagem rápida, teste perto de você" esteve a cargo de Denise Ribeiro Franqueira Pires (Gerência de DST/AIDS-SES/ RJ) e a coordenação técnica executiva com André RS Périssé (DCB/ENSP/Fiocruz) e Nélio Zuccaro (SES/RJ), sendo financiado pela AIDS Healthcare Foundation (AHF). Este programa foi implementado de 2016 a 2018, quando sofreu uma interrupção com o corte orçamentário da AHF.

(d) Os 16 pesquisadores envolvidos no trabalho de campo compuseram um perfil variado quanto à geração, gênero, orientação sexual e inserção no campo (pontual ou regular). Tal diversidade potencializou a troca de informações, aprofundamento teórico-metodológico e a produção de resultados a partir de múltiplos olhares. 
focais com profissionais dos serviços de saúde, um por município, e um grupo focal com lideranças comunitárias do movimento LGBT da região. Por meio dessas estratégias, mapeamos a configuração da rede de saúde e instâncias de articulação com outros setores; o histórico de açóes e campanhas preventivas das ISTs/Aids; as experiências dos programas de Aids com as populações-chave; os treinamentos recentes das equipes de saúde envolvidas com HIV/Aids; e as ações de testagem de HIV e cuidado, incluindo as de assistência social (Cras, Creas), de ONGs e grupos religiosos ${ }^{11}$.

Foram realizadas ainda 29 entrevistas individuais com gays; e mulheres trans/ travestis e prostitutas, prioritariamente de 18 a trinta anos e moradores dos três municípios, sobre as condições de vida e a vulnerabilidade ao HIV. O acesso aos gays e trans/travestis resultou de indicaçóes de profissionais, principalmente do Centro de Referência LGBT da Baixada, de lideranças do movimento social e de informantes locais. A maioria das prostitutas foi contatada nos estabelecimentos de prostituição ou indicadas por profissionais de saúde dos municípios.

Foram realizadas observações participantes em locais de prostituição - dois estabelecimentos e um posto de combustível na rodovia interestadual que atravessa os municípios - e nas paradas e atividades relativas ao dia do Orgulho LGBT. O mapeamento das diferentes redes nas quais as populaçóes estudadas se inserem foi complementado por um levantamento exploratório de aplicativos de interação virtual usados por gays/HSHs e travestis, de sites de anúncios de prostituição na Baixada Fluminense e de fóruns virtuais de clientes.

A pesquisa foi aprovada pelo Comitê de Ética em Pesquisa da Fiocruz (no 45267315.9.0000.5248) e seguiu os procedimentos éticos previstos.

Os três municípios diferem quanto a sua extensão, densidade populacional, economia e PIB per capita. Todavia, são regidos pelas mesmas políticas de saúde do Ministério e acompanhados pela SES. A estrutura e funcionamento dos programas municipais de HIV/Aids são semelhantes, embora haja particularidades em termos de recursos materiais e humanos disponíveis e capacidade operacional. Com relação à oferta de testagem e aconselhamento, prevenção e tratamento ao HIV/ Aids, encontramos mais semelhanças do que diferenças, que serão explicitadas na apresentação dos resultados.

\section{A ampliação da oferta de testagem de HIV}

Um aspecto observado na resposta programática local ao HIV refere-se ao acento especial nas atividades de testagem para a população geral. Conforme relatado pelos profissionais e gestores, não faltam insumos para o diagnóstico e capacitação em testagem. Embora haja uma diferenciação entre os três municípios em termos da estrutura e funcionamento da rede de saúde, a ampliação da oferta de teste e sua capilarização na rede pública constituem um traço comum entre eles. Os programas locais de Aids têm promovido treinamentos sobre o manejo de novas tecnologias diagnósticas (como teste rápido e teste fluido oral) e a distribuição de insumos médicos para toda a rede básica de saúde, visando atender a política nacional de descentralização da testagem e assistência às pessoas vivendo com HIV/Aids (PVHA). Tais investimentos, no entanto, encontram obstáculos de ordem estrutural que se impóem aos serviços, como escassez e intensa rotatividade de recursos humanos e 
burocracia para execução dos recursos. Ainda que os especialistas busquem seguir o que é prescrito nas diretrizes globais e nacional, as ações de testagem nos municípios estudados ocorrem segundo condiçóes variáveis.

Os documentos do Ministério da Saúde ${ }^{1,3}$ sublinham a importância de que as açôes se estruturem em função das especificidades locais da epidemia, incluindo as situaçôes mais típicas de risco e vulnerabilidade. Todavia, um dos desafios enfrentados por gestores se refere à disponibilidade de dados atualizados capazes de orientar o planejamento do trabalho. Foi relatado que a sistematização dos registros da Vigilância Epidemiológica e da Superintendência de Programas e Atenção Básica dos municípios não é suficiente para orientar e avaliar as ações. Além da divulgação das estatísticas da Gerência Estadual não ser regular, não foi referida a consulta a dados sociodemográficos da região disponibilizados pelo IBGE e Ipea. Em suma, nem sempre as açôes se orientam segundo a identificação de necessidades locais.

O planejamento das atividades tem sido efetivamente determinado por demandas mais imediatas aos serviços e ordens motivadas por condicionantes políticos. Como observado no trabalho de campo, a organização das ações de testagem e prevenção ao HIV depende de orientações políticas e dotação orçamentária que, em geral, são desestabilizadas a cada mudança de governo no âmbito municipal, estadual e federal. Nesse sentido, as açôes em HIV/Aids tendem a ser percebidas menos como "políticas de Estado" e mais como "políticas de governo".

Segundo os depoimentos dos profissionais, a estrutura dos serviços tem sido satisfatória para atender à demanda de testagem e tratamento: não faltam kits de testagem, não há filas, o aconselhamento é realizado e os resultados não atrasam. A ampliação da oferta de testagem não é vista por eles como um problema, pois sua capilarização na rede assistencial não implicou sobrecarga aos serviços. No entanto, advertem que os recursos humanos trabalham em sua capacidade máxima e que o incremento e diversificação da oferta de teste de HIV, por meio da implementação de UMTs, exigiria a ampliação de recursos humanos - sobretudo de profissionais de medicina e de saúde mental - e melhoria dos sistemas de referenciamento para acolher o contingente de usuários para tratamento. Assinalam ainda ser necessário fortalecer os processos de trabalho de equipe e os esforços intersetoriais para garantir a continuidade do tratamento das PVHA e a oferta de consultas com especialistas.

Todavia, o cenário atual é pouco propício para o cumprimento dessas expectativas frente aos cortes orçamentários no setor saúde decorrente das recentes crises econômica e política no âmbito nacional e do estado do Rio de Janeiro, em particular. Ademais, segundo profissionais e gestores, houve nos últimos anos um apagamento da Aids como problema social. A introdução dos antirretrovirais e a consequente cronificação da doença é vista, paradoxalmente, como um fator de diluição do sentido de gravidade da epidemia, deixando de ser uma questão pública prioritária. Isso implicou na redução de açốes de prevenção de caráter estrutural e educativo, de recursos para campanhas educativas e de formação de recursos humanos, sobretudo médicos, e na menor presença de ONGs locais. Por outro lado, vem se fortalecendo um modelo de resposta mais clínico e de predomínio médico.

Os gestores lidam com orçamentos limitados e baixíssima integração com as universidades e os meios de comunicação na resposta local à epidemia. Essa situação contrasta com a descrição sobre as políticas e ações de enfrentamento ao HIV nas 
décadas de 1990 e 2000, quando os meios de comunicação, a academia e o Estado expressavam um vigoroso interesse sobre a Aids e mobilizavam-se projetos variados, parcerias e respostas comunitárias. Segundo alguns gestores, os recursos eram maiores, o que favoreceu a consolidação dos programas locais de Aids, vistos como privilegiados por outros programas e unidades de saúde locais. Além disso, gestores indicam que havia uma forte discussão sobre sexualidade e inovação em termos de respostas programáticas de caráter educativo e estrutural.

Atualmente, constata-se uma menor destinação de recursos, baixíssima integração com as universidades e meios de comunicação e menor oferta de ações educativas e mobilização social. Esse quadro diz respeito à capacidade institucional local, mas não somente. A virada biomédica no campo da Aids parece reforçar uma concepção difusa de que é possível responder à epidemia colocando como eixo organizador de todas as açôes as dinâmicas e regras típicas do trabalho clínico-assistencial.

\section{Desafios das ações focalizadas}

Outro hiato entre as diretrizes nacionais e a resposta programática local refere-se à atenção focalizada nas denominadas populaçóes-chave. A despeito do Ministério da Saúde preconizar ações preventivas voltadas para populações-chave $e^{2,12,13}$, suas necessidades particulares não são consideradas no planejamento das açóes locais de prevenção e testagem. Notamos que nos municípios não há um histórico de debates e ações sobre a prevenção para esses grupos, tampouco divulgação de oferta de PEP e PrEP. Tal situação é corroborada pela falta de estudos locais sobre essas populações e de posicionamento de setores e lideranças LGBT no tema da Aids, característica comum aos três municípios.

Os gestores justificam a insuficiência de ações de testagem específicas para esses grupos em função das dificuldades para identificá-los ou se aproximar deles. Muitos profissionais expressam dúvidas sobre os grupos marginalizados sexualmente, em termos de suas experiências, práticas e identidades. Eles indicam estar habilitados para informar sobre as formas de transmissão e proteção do HIV, mas parecem despreparados para abordar temas sobre sexualidade. Afirmam não haver treinamentos e capacitaçốes a esse respeito e que a rotina dos serviços não favorece a abordagem ao assunto.

Um limitador adicional para o desenvolvimento de ações de saúde focalizadas tem sido as resistências para posicionar a discriminação de LGBT e outros temas relativos à sexualidade na agenda pública local; mesmo diante da recente criação de secretarias municipais encarregadas de articular políticas publicas de defesa de direitos dessas populaçôes. Vale salientar que os três municípios têm forte influência das religiôes evangélicas neopentecostais nas estruturas de poder, o que confere um perfil político conservador e limita o desenvolvimento de políticas públicas mais progressistas para a população LGBT e mulheres.

Frente ao perfil do contexto local e o temor da discriminação, gays, outros HSHs e prostitutas nem sempre comentam sobre suas práticas sexuais nas consultas, sendo atendidos pelos profissionais como população geral. Tampouco nas atividades extramuros a dificuldade de abordar tais grupos logra ser superada. A ausência de bares, boates e locais de sociabilidade voltados para esse público nos municípios, somada à 
escassa presença de organizaçôes sociais LGBT, também limita as possibilidades de aproximação. $\mathrm{O}$ acesso aos estabelecimentos ou áreas de prostituição exige negociações com os donos ou com as mulheres e travestis. Nem sempre há recursos humanos disponíveis para esse tipo de ação, seja pela sobrecarga de trabalho ou por temores relativos à segurança.

Nesse contexto, as açôes de estímulo à testagem enfrentam o desafio de alcançar essas populaçóes sem gerar uma visibilidade indesejada e sem contribuir para a sua associação com a Aids. Segundo seus relatos, há uma expectativa generalizada de que os mecanismos de confidencialidade dos resultados do teste nas UMTs fossem reforçados, dado que a ação ocorre em um espaço público. No caso das pessoas que vão fazer o teste em grupo, a entrega do resultado em segredo se torna difícil. Além disso, a possibilidade de coação para identificar o estado sorológico surge nos relatos como importante preocupação. Prostitutas ressaltam que um dos perigos potenciais da oferta de testagem móvel é a pressão por parte de clientes, gerentes ou donos de estabelecimento.

As demandas de saúde das populaçóes entrevistadas apontam para a importância da diversificação de serviços, o que coincide com a proposta de respostas mais amplas às situaçôes de vulnerabilidade ao HIV. As trans/travestis, em particular, expressam que o teste de HIV isoladamente não responde às suas necessidades de saúde. Diante da precariedade dos serviços do SUS, elas têm expectativa de que a UMT ofereça outros exames clínicos, como aferição de pressão arterial e encaminhamento para os serviços especializados. Entre trans/travestis e mulheres trabalhadoras sexuais, há bastante interesse por atividades educativas que abordem os aspectos clínicos associados à prática sexual frequente e às ISTs e informaçôes sobre tratamento diante do diagnóstico positivo do HIV. O acolhimento dessa população de forma integral foi verificado em um dos municípios em que havia uma parceria entre os programas de ISTs/Aids e as equipes dos Consultórios na Rua. Cabe igualmente assinalar a demanda das trans/ travestis por orientaçóes sobre procedimentos burocráticos para mudança de nome e a interação de hormônios e medicamentos antirretrovirais.

\section{Da distância entre o testar e o tratar}

Como assinalado, o binômio testar e tratar equivale, em termos práticos, à síntese da estratégia denominada Tratamento como Prevenção $(\mathrm{TcP})^{1,3}$. Nela, a testagem, mais que uma ação individual, é atrelada ao tratamento e assume uma função primordial de controlar a transmissão do HIV no âmbito populacional. No entanto, a pesquisa realizada na Baixada Fluminense permitiu identificar que a sequência entre a testagem e o tratamento nem sempre é tão linear e automática como pode sugerir a descrição das diretrizes técnicas. Além disso, o significado preventivo da testagem não é autoevidente para todos os profissionais envolvidos com sua consecução. Assim, o estudo permitiu evidenciar a diversidade de elementos que compóem as vicissitudes da execução das políticas globais de $\mathrm{Aids}^{14}$.

Um primeiro aspecto a ressaltar se refere à concepção dos trabalhadores em saúde sobre a execução das novas políticas de prevenção. Segundo os relatos dos profissionais que realizam a testagem nas unidades básicas, a ampliação da oferta é entendida como uma garantia do direito do usuário ao diagnóstico precoce e ao tratamento, 
tendo como principal vantagem a redução do diagnóstico tardio e das complicações da infecção. Não obstante, o estímulo à testagem não tem para eles um sentido de prevenção e controle epidemiológico populacional; ou seja, não identificam uma associação entre a intensificação da oferta de testagem com a meta de redução da circulação do HIV e a interrupção da cadeia de transmissão, prevista nas políticas atuais.

A realização da testagem nos serviços é entendida, sobretudo, como uma oportunidade para promover o diálogo e a reflexão sobre os contextos de risco e vulnerabilidade; mais característica de abordagens de prevenção hoje consideradas tradicionais, e menos com o sentido preconizado pelo TcP. Esse dado sugere a coexistência de diferentes racionalidades de prevenção que se tensionam no âmbito local. Considerando a intensidade com que modelos de prevenção baseados no uso do preservativo e na testagem atrelada ao aconselhamento, foram construídos no Brasil, é compreensível que a introdução de novas estratégias, como a TcP, seja interpretada à luz dos modelos preconizados anteriormente. Tal fato aponta para a complexidade envolvida nos processos de renovação das políticas de Aids.

Outra vicissitude que torna menos linear a relação entre o testar e o tratar referese aos fatores que comprometem a adesão dos usuários ao tratamento. Com base nas práticas clínicas, os profissionais descrevem várias situações que dão um caráter descontínuo ao encadeamento da testagem com a remissão ao tratamento e a sua adesão, até a carga viral se tornar indetectável. Destacam-se as dificuldades dos usuários para lidar com o diagnóstico, as exigências da rotina dos novos cuidados de saúde e os efeitos colaterais da terapia medicamentosa.

Nessa direção, convém salientar os relatos acerca do estigma da Aids e suas implicaçôes para a retenção da pessoa diagnosticada ao tratamento. Ainda que os profissionais busquem construir junto com os usuários a imagem da Aids como uma doença crônica, persistem os temores referentes à revelação do diagnóstico, à possibilidade de fragilidade física e ao juízo moral vinculado à infecção pelo vírus. Isso se confirmou entre nossos entrevistados, quando optam, por exemplo, por um local de testagem e atendimento distante da área de moradia, na tentativa de garantir o anonimato em relação à família, à comunidade e aos eventuais profissionais conhecidos.

O impacto emocional do diagnóstico é mencionado pelas equipes e pela população entrevistada como uma barreira importante para o tratamento e a vinculação do usuário ao sistema de saúde após o teste. Tais achados confirmam que o diagnóstico ainda é considerado uma experiência crucial na vida dos usuários, reformulando sua posição na família, no trabalho e impondo uma gestão da informação ${ }^{15}$.

A despeito das implicações do estigma da Aids, seu enfrentamento se apresenta como um importante desafio no cumprimento das diretrizes do TcP. Alguns profissionais demonstram preocupação com uma eventual banalização do diagnóstico, frente às promessas de eficácia dos antirretrovirais. Em suma, não obstante os discursos da Aids enfatizarem seu caráter de doença crônica, persistem os temores dos usuários com o estigma associado à infecção pelo vírus. Os relatos de entrevistados(as) com sorologia positiva do HIV indicam a preocupação de manter sua condição em segredo da família e do ambiente profissional e comunitário. Tais temores distanciam as pessoas estudadas do teste e dificultam a adesão dos soropositivos ao tratamento antirretroviral. 


\section{Alcance das combinações na "Prevenção combinada"}

Uma das perguntas do estudo foi como a estratégia global denominada "Prevenção combinada ao HIV" vinha se concretizando no âmbito local. A resposta a ela é especialmente cara, pois exige identificar os efeitos da introdução das novas tecnologias e a sua relação com outras estratégias de prevenção existentes, como promoção do preservativo e aquelas de caráter estrutural.

A "Prevenção combinada" é apresentada oficialmente como a integração de diferentes abordagens de prevenção - biomédica, comportamental e socioestrutural - que, ao serem acionadas simultaneamente, visam atingir múltiplos âmbitos da transmissão do HIV (individual, parcerias/relacionamentos, comunitário e social) ${ }^{3}$. As combinações objetivam atender às necessidades específicas de determinados públicos e contextos ${ }^{(e)}$. Na página do Departamento de Vigilância, Prevenção e Controle das IST, do HIV/AIDS e das Hepatites Virais (DIAHV), é comum encontrar imagens como a "mandala da prevenção" (figura 1) e o "cubo mágico" (figura 2) para ilustrar o conjunto de estratégias e a potencialidade de sua combinação. Dado que a política de prevenção combinada preconiza a complementariedade de abordagens, tem-se questionado sobre o quanto a implementação dessa proposta tem sido efetivamente diversificada e combinada ${ }^{7}$.

Figura 1. Mandala da prevenção

Fonte: http://www.aids.gov.br/pt-br/publico-geral/previna-se (Extraída em 15/07/2018)

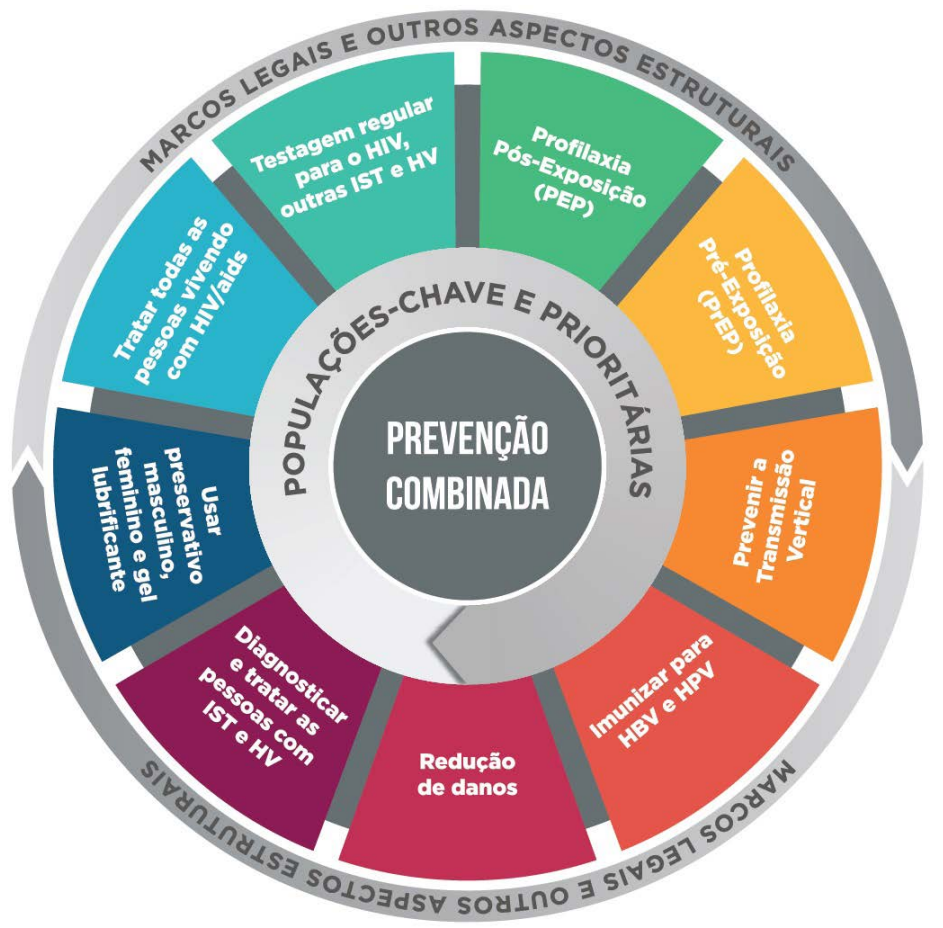

Figura 2. Cubo mágico

Fonte: http://www.aids.gov.br/pt-br/publico-geral/prevencao-combinada/o-que-e-prevencao-combinada_ (Extraída em 15/07/2018) (e) Conferir: http://www. aids.gov.br/pt-br/gestores/ organizacao-dos-servicos/ diretrizes-nacionais-deprevencao-combinada-emhivaids 


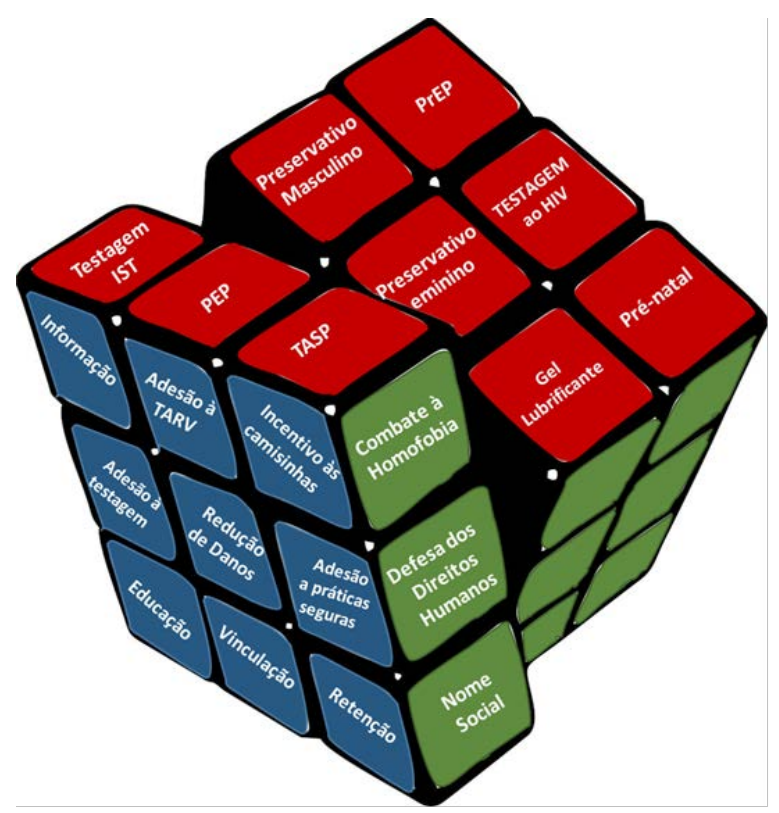

Para entender a efetivação da prevenção combinada cabe abordar o lugar atribuído ao uso do preservativo no conjunto de estratégias empregadas. Nos três municípios, a distribuição de preservativos tem sido mantida. Tal recurso goza de protagonismo entre os profissionais e a população, a despeito da ênfase das políticas recentes nas novas estratégias e tecnologias de prevenção do HIV. No contexto estudado, o preservativo é a tecnologia de prevenção de maior difusão, em grande parte devido à política de distribuição universal. $\mathrm{O}$ acesso gratuito e a grande disponibilidade favorecem com que o preservativo alcance locais distantes dos órgãos públicos, movimentando uma rede ampla de instituições e atores sociais. Por meio de contatos institucionais e pessoais, a denominada "camisinha do posto [de saúde]" sai das unidades de saúde e chega até bairros sem cobertura de serviços, vindo a ser ali a presença mais tangível do Estado. Sua abrangência chega até os locais de prostituição, mesmo quando estes não estavam entre os pontos de distribuição registrados pelos serviços.

A importância do preservativo no contexto local pode ser depreendida pelos seus múltiplos sentidos. Além de ser uma tecnologia de barreira, funciona como um ícone das mensagens de prevenção, lembrando às pessoas da possibilidade de infecção ou dinamizando conversas sobre o tema. Nas açôes de prevenção locais, observamos que a distribuição do preservativo eventualmente compensava a falta de material educativo. No contexto de prostituição, por exemplo, a camisinha é a opção de prevenção mais conhecida e, de acordo com os relatos, o uso é bastante consistente. Segundo as mulheres contatadas, as várias camisinhas disponíveis em uma caixa no balcão dos estabelecimentos representavam por si só uma mensagem, aviso ou lembrança sobre a vigência da Aids, das IST e da importância da prevenção. Observamos assim que o preservativo masculino está integrado aos "programas", sendo previamente cobrado ao cliente e levado pela mulher para a cabine ou quarto. Seu uso pode até ser renegociado na privacidade da cabine/quarto, mas os estabelecimentos garantem as condiçóes para que a profissional do sexo exerça a autonomia de decidir sobre sua utilização.

Para entender o alcance da prevenção combinada, indagamos também sobre o lugar das estratégias de prevenção de caráter educativo no contexto local. Estas recebem um investimento mais limitado em comparação com o que é aplicado nas açôes de 
testagem. As iniciativas limitam-se ao desenvolvimento de atividades educativas multissetoriais com a população escolar ("Projeto saúde e prevenção nas escolas") ${ }^{(\mathrm{f})} \mathrm{e}$ palestras/oficinas com empresas locais. Os profissionais desenvolvem ainda campanhas de prevenção em datas especiais (como no dia $1^{\circ}$ de dezembro e no Carnaval). No entanto, frente à carência de cartazes, cartilhas e panfletos, as campanhas têm integrado basicamente a oferta de testagem e/ou distribuição de preservativo. Segundo os gestores, a produção de material educativo é prejudicada pelos entraves burocráticos da gestão pública e problemas estruturais dos serviços, como a falta de disponibilidade de recursos humanos para atender às demandas de educação em saúde.

Outro desafio da prevenção combinada no âmbito local diz respeito à consecução de abordagens estruturais capazes de enfrentar os problemas de marginalização social, estigma e discriminação sexual, associados à vulnerabilidade e diagnóstico do HIV/ Aids. Tais abordagens são apontadas pelos gestores dos programas de Aids locais como uma de suas principais carências. Para citar um exemplo, a moralidade sexual foi mencionada como um fator negativo para acesso aos serviços e aos recursos biomédicos de prevenção.

O alcance da "Prevenção combinada" pode ser pensado também a partir da capacidade de atuação de organizaçóes comunitárias na resposta local à Aids e o tipo de relação que estabelecem com o setor saúde. Nos municípios estudados, as atividades de apoio às PVHA são realizadas por duas associaçôes comunitárias da região, que conduzem ações de caráter assistencial (suporte emocional, segurança alimentar, acesso à saúde e benefícios sociais). Tais ações atendem, em parte, demandas da população não contempladas pelos programas municipais de Aids e pela rede assistencial governamental. Chama a atenção que a colaboração estabelecida entre essas associações e os programas de Aids locais inclua o apoio às atividades de ampliação de acesso ao teste de HIV e sífilis.

Por um lado, as poucas organizaçóes sociais de Aids têm importante papel de colaboração nas iniciativas de testagem e na atuação nos conselhos municipais de saúde para garantir o direito à assistência e a segurança alimentar. Mas, por outro lado, o papel tradicional de crítica e controle social sobre as novas políticas de prevenção demonstrou-se mais reduzido. Suas açôes têm um foco acentuado nas respostas às necessidades de tipo assistencial e na colaboração com as metas de expansão da testagem. Esse panorama contrasta com o papel histórico do movimento social de maior protagnonismo nas respostas à epidemia ${ }^{16}$, sugerindo mudanças que não podem ser dissociadas de uma reconfiguração maior do campo. Soma-se a esse cenário a baixa presença de ONGs feministas, LGBT e de HIV/Aids na região. As organizações existentes enfrentam falta de sede e financiamento, mantendo-se pela iniciativa de poucos militantes; o que confere ao movimento social um caráter mais pessoalizado.

Quanto às populaçóes-chave, cabe destacar o trabalho do Centro de Referência LGBT da Baixada Fluminense (CR-LGBT) na defesa dos direitos sexuais e apoio social à população sexualmente marginalizada ${ }^{17}$. Integrado ao "Programa Rio sem homofobia”, do governo estadual, o trabalho do CR-LGBT era estratégico para posicionar publicamente as necessidades dessa população. $\mathrm{Na}$ administração das prefeituras locais, sua implementação estimulou inclusive a conformação de subsecretarias e departamentos de atenção a populações que sofrem discriminação sexual. Não obstante, mesmo com potencial para colaborar com a efetivação de uma (f) Conferir: http://portal.mec. gov.br/projeto-saude-e-prevencao-nas-escolas-spe 
estratégia de prevenção combinada ao HIV, sua parceria com o setor saúde era reduzida ao apoio à realização de ações de testagem extramuros.

Segundo o DIAHV, a prevenção combinada deve incluir a oferta de PEP e PrEP, sendo a primeira indicada para casos de acidentes ocupacionais e para todas as formas de exposição sexual ${ }^{12}$, enquanto a segunda é recomendada para as populações consideradas chave ${ }^{13}$. Segundo os gestores e profissionais, a demanda espontânea local pela PEP é mínima, possivelmente pelo fato de ser recente, inexistir divulgação a respeito e dos municípios contarem com poucas unidades que disponibilizam o serviço - apenas um oferece a PEP em todas as unidades com pronto atendimento. Salientamos que tal oferta era pouco conhecida pelas populaçóes-chave e lideranças comunitárias entrevistadas. Quando à PrEP, até 2016 ela não estava disponível na Baixada, pois encontrava-se em fase experimental no país.

Entre as prostitutas, a maioria desconhecia a oferta da PEP na rede pública. Mesmo as que sabiam da disponibilização da profilaxia nos serviços de saúde, julgavam que esta fosse reservada para casos de violência sexual. Apenas duas já haviam realizado a PEP, uma por conhecimento prévio e a outra por indicação de funcionárias do estabelecimento onde trabalhava. A maioria das trans/travestis não tinham informações sobre as profilaxias pós e pré-exposição ao HIV. Apenas uma teve experiência com PEP, mas não concluiu o tratamento devido aos efeitos colaterais. A maioria dos gays entrevistados relatou familiaridade com o emprego de medicamentos antirretrovirais como meio de prevenção, mas apenas dois tinham feito uso de PEP. Nesse caso, tais informaçóes foram obtidas em ONGs, mídia, redes sociais e paradas gays. Os serviços de saúde não foram mencionados como difusor dessa informação.

\section{Considerações finais}

As políticas globais e nacional ao HIV/Aids passaram na última década por uma significativa transformação, marcadas por uma ênfase na ampliação da testagem e pela introdução dos antirretrovirais para fins de prevenção. A tradução dessas diretrizes para o âmbito local vem suscitando muitos desafios. A descrição das repostas programáticas nos municípios estudados e das experiências de gays, trans/travestis e prostitutas no campo da prevenção e do cuidado do HIV revela hiatos entre o plano normativo e o das práticas cotidianas. $\mathrm{O}$ olhar da pesquisa socioantropológica às engrenagens mobilizadas na proposição e uso das estratégias de prevenção ajudaram a delimitar essa problematização.

Como buscamos demonstrar, os sentidos da oferta de tecnologias como o teste rápido, a PEP e a PrEP são indissociáveis de sua aplicação prática. Seus significados vão além de seus mecanismos de ação e benefícios clínicos. Quer dizer, a simples disponibilidade dessas novas estratégias não é capaz por si só de suplantar os problemas relativos à sua implementação e à necessidade de investimentos na estrutura dos serviços públicos, na formação dos profissionais e na luta política por direitos e enfrentamento do estigma. Sua efetivação exige considerar as especificidades sociais e históricas do contexto em que serão aplicadas. Como destacado por outros autores, todas as intervenções de prevenção do HIV têm em comum o fato de sua condução estar sempre relacionada com a vida social das pessoas e, nesse sentido, reiteram 
a artificialidade da separação discricional entre intervenção biomédica e social7 ${ }^{71}$. Portanto, para compreender a efetividade das abordagens preventivas, incluindo aquelas chamadas de biomédicas, cabe considerar sua integração com as experiências e práticas sociais.

$\mathrm{O}$ TcP e as profilaxias pós e pré-exposição não tornam prescindível a abordagem de questôes de ordem subjetiva e social relativas às problemáticas de gênero e sexualidade que incidem sobre a prevenção e o cuidado. A compreensão dessas estratégias e tecnologias é indissociável das dinâmicas humanas que envolvem seu uso comum. O presente artigo pretende ser uma contribuição para a compreensão sobre a ensamblagem social dos processos técnicos e das tecnologias empregados na resposta à epidemia.

Este estudo permitiu demonstrar ainda o potencial da pesquisa social no momento atual da resposta à Aids. Sua contribuição vai além de um diagnóstico local, com recomendações para a ampliação da testagem de HIV em grupos populacionais específicos. Buscamos assinalar como as ações de prevenção do HIV e cuidado das PVHA se configuram socialmente em contextos específicos e como seus sentidos se articulam a sistemas de desigualdades sociais. A concretização das atuais políticas não pode negligenciar os vetores sociais da epidemia, como as desigualdades de gênero, a homofobia e transfobia e os processos de estigmatização relativos à Aids e à prostituição.

Em suma, buscamos evidenciar a dimensão relacional, simbólica e política que perpassa a implementação de intervençôes biomédicas preconizadas nas atuais políticas de controle da Aids. Desse modo, reiteramos como a consecução dessas intervençóes na vida cotidiana envolve processos sociais que precisam ser considerados no atual enfrentamento da epidemia.

\section{Contribuições dos autores}

Ambos os autores participaram ativamente de todas as etapas de elaboração do manuscrito.

\section{Agradecimentos}

Somos gratos aos coordenadores e profissionais dos programas municipais de DST/ Aids, das equipes do Consultório na Rua, do Centro de Referência da Cidadania LGBT Baixada I e do Centro Especializado de Atendimento à Mulher (CEAM). Agradecemos ainda aos representantes das ONGs Aids locais e de defesa da população LGBT e aos grupos populacionais entrevistados, bem como o apoio do Instituto Oswaldo Cruz/ Fiocruz e da Aids Healthcare Foundation (AHF).

\section{Direitos autorais}

Este artigo está licenciado sob a Licença Internacional Creative Commons 4.0, tipo BY (https://creativecommons.org/licenses/by/4.0/deed.pt_BR). 


\section{Referências}

1. The Joint United Nations Programme on HIV/AIDS (UNAIDS). 90-90-90 An ambitious treatment target to help end the AIDS epidemic. Geneva: UNAIDS; 2014.

2. The Joint United Nations Programme on HIV/AIDS (UNAIDS). Combination HIV prevention: tailoring and coordinating biomedical, behavioral and structural strategies to reduce new HIV infections. A UNAIDS discussion paper. Geneva: UNAIDS; 2010.

3. Brasil. Ministério da Saúde. Secretaria de Vigilância em Saúde. Departamento Nacional de DST, Aids e Hepatites Virais. Prevenção combinada do HIV: bases conceituais para profissionais, trabalhadores e gestores de saúde. Brasília, DF: Ministério da Saúde; 2017.

4. World Health Organization. Consolidated guidelines on the use of antiretroviral drugs for preventing and treating HIV infection. Geneva: WHO; 2013.

5. Montaner JS, Lima VD, Harrigan PR, Lourenço L, Yip B, Nosyk B, et al. Expansion of HAART coverage is associated with sustained decreases in HIV/AIDS morbidity, mortality and HIV transmission: the «HIV treatment as prevention» experience in a Canadian setting. PLoS One. 2014; 9(2):e87872.

6. Monteiro S, Brigeiro M, Villela W, Mora C, Parker R. Desafios do tratamento como prevenção do HIV no Brasil: uma análise a partir da literatura sobre testagem. Cienc Saude Colet. 2019; 24(5):1793-1807.

7. Kippax S, Stephenson N. Beyond the distinction between biomedical and social dimensions of HIV: Prevention through the lens of a social public health. Am J Public Health. 2012; 102(5):789-99.

8. Aggleton P, Parker R. Moving beyond biomedicalization in the HIV response: implications for community involvement and community leadership among men who have sex with men and transgender people. Am J Public Health. 2015; 105(8):1552-8.

9. Peirano M. Etnografia não é método. Horiz Antropol. 2014; 20(42):377-91.

10. DaMatta R. Aventura sociológica. Rio de Janeiro: Zahar; 1978. Ofício do etnólogo ou como ter anthropological blues; p. 23-35.

11. Monteiro S, Brigeiro M. Testagem e prevenção do HIV/AIDS na Baixada Fluminense: potencialidades e desafios. Rio de Janeiro: FIOCRUZ/IOC; 2017.

12. Brasil. Ministério da Saúde. Protocolo clínico e diretrizes terapêuticas para profilaxia pós-exposição (PEP) de risco à infecção pelo HIV, IST e hepatites virais. Brasília, DF: Ministério da Saúde; 2017.

13. Brasil. Ministério da Saúde. Protocolo clínico e diretrizes terapêuticas para profilaxia pré-exposição (PrEP) de risco à infecção pelo HIV. Brasília, DF: Ministério da Saúde; 2017.

14. Biehl J. Antropologia no campo da saúde global. Horiz Antropol. 2011; 17(35):25796.

15. Stangl A, Lloyd J, Brady L, Holland C, Baral S. A systematic review of interventions to reduce HIV-related stigma and discrimination from 2002 to 2013: how fare have we come? J Int Aids Soc. 2013; 16 Suppl 2:18734.

16. Ramos $\mathrm{S}$. O papel das ONGs na construção de políticas de saúde: a aids, a saúde da mulher e a saúde mental. Cienc Saude Colet. 2010; 9(4):1067-78. 
17. Carrara S, Aguião S, Lopes P, Tota M. Retratos da política LGBT no Estado do Rio de Janeiro. Rio de Janeiro: CEPESC; 2017.

18. Chang LW, Serwadda D, Quinn TC, Wawer MJ, Gray RH, Reynolds SJ. Combination implementation for HIV Prevention: moving from evidence to population-level impact. Lancet Infect Dis. 2013; 13(1):65-76.

Global and national AIDS response policies emphasize treatment as prevention, pre and postexposure prophylaxis, and combination prevention. This article analyzes the implementation of such policies at local level drawing on the findings of a social study conducted in municipalities in the metropolitan region of Rio de Janeiro, Brasil, centered on HIV/AIDS prevention and care and the vulnerability of gays, transvestites, and prostitutes. The gaps between policy and local action are addressed focusing on four issues: the expansion of HIV testing, challenges facing targeted actions, the distance between testing and treatment, and the reach of combinations in combination prevention. We demonstrate the importance of understanding the social processes that cut across the implementation of the global recommendations and guidelines and suggest that these processes must to be taken into account to effectively tackle the HIV/AIDS epidemic.

Keywords: HIV/AIDS. Treatment as prevention. Combination prevention. Social research. Rio de Janeiro.

Las políticas globales y nacional de respuesta al Sida han enfatizado actualmente el tratamiento como prevención, las profilaxis post y preexposición al VIH y la prevención combinada. El artículo analiza la traducción de esas políticas en el ámbito local, con base en una investigación social en municipios de la región metropolitana de Río de Janeiro, Brasil, centrada en el contexto programático de prevención y cuidado del VIH/Sida y la vulnerabilidad al VIH de gais, travestis y prostitutas. Los hiatos entre las directrices y los contextos locales se abordan a partir de cuatro temas: ampliación de la oferta de testes, desafíos de las acciones focalizadas, la distancia entre el teste y el tratamiento y el alcance de las combinaciones en la prevención combinada. Buscamos demostrar la importancia de la comprensión de los procesos sociales presentes en la implementación de las estrategias preconizadas globalmente que todavía tienen que llevarse en consideración en el enfrentamiento de la epidemia.

Palabras clave: VIH/Sida. Tratamiento como prevención. Prevención combinada. Investigación social. Río de Janeiro. 